\title{
Past Global Changes: 30 years of paleoscience to help save the planet
}

\author{
Hubertus Fischer' ${ }^{1}$ S. Fritz ${ }^{2}$ and A. Mix ${ }^{3}$
}

Without the reconstruction of past global changes and the knowledge of the processes that control them, future longterm alterations in components of the Earth system cannot be reliably predicted. Over the last three decades, PAGES has dedicated its work to provide this information to the global science community.

\section{Early visionaries}

In 1972, the Club of Rome published its first report on "The Limits to Growth" (Meadows et al. 1972). It received substantial public attention and raised awareness that our use of global natural resources at an everincreasing speed is not sustainable and that planetary boundaries set limits to economic growth. At the same time, more and more scientists across the globe engaged in quantifying the ongoing human impacts on climate and the environment, improving our understanding of the Earth system, and implementing these processes in Earth system models to predict Earth's future evolution. In the decades following the Club of Rome report, the International Council for Science (ICSU) and the International Social Science Council (ISSC) initiated four global programs to organize the huge task of global change research: the World Climate Research Programme (WCRP), quantifying physical changes in the climate system; the International Geosphere-Biosphere Programme (IGBP), studying changes in biogeochemical cycles; DIVERSITAS concentrating on changes in biodiversity; and the International Human Dimensions Programme (IHDP), addressing the impact of these changes on human societies and their well-being.

Some early visionaries from the paleoclimate field immediately realized that documentation of contemporary changes alone was not sufficient to assess the impact of human interference with the Earth system, particularly because many components of the system act on timescales much longer than the era of direct scientific observations (which are typically limited to a few decades or, in some cases, a few centuries). Some examples of such long-timescale components include glaciers and ice sheets, natural biogeochemical cycles, ecosystems and food chains, or ocean circulation. Most importantly, these are also all components that are crucial for the robust long-term prediction of climate, greenhouse gas forcing, and ecosystem response. Moreover, they are key to assessing the impact of anthropogenic changes on human well-being, which is affected by processes such as sea-level rise, water supply/desertification, heat waves and other extreme events, ecosystem structure and function, or agriculture.

Among the early visionaries in the early effort to incorporate paleoperspectives into global change studies were
John A. (Jack) Eddy, a US solar scientist, and Hans Oeschger, a Swiss climate physicist (Fig. 1), who together chaired a special IGBP working group on "Techniques for Extracting Environmental Data from the Past". This working group met for the first time in 1988 in Bern, Switzerland, and included a "who's who" of paleoclimate researchers at that time. It was not an easy feat to assemble all those illustrious names in one room and to glue them together to work towards a common goal, but Oeschger and Eddy succeeded. Only a year later, an even larger workshop was organized in Snowmass, Colorado, USA. Those were the "good old times" when all participants were paid to attend, and it certainly helped in bringing the brightest "paleominds" together. The Snowmass workshop led to the report "Global Changes of the Past" (Bradley 1989) and may be regarded as the birth of PAGES, the IGBP Core Project on Past Globa Changes. PAGES was officially launched two years later in 1991, with the goal to use the paleorecord to inform the global-change debate on long-term changes, processes, and risks in the Earth system.

An achievement just as impressive as bring ing a large part of the paleocommunity together within PAGES was that Eddy and Oeschger managed to convince both the US National Science Foundation (NSF) and the Swiss National Science Foundation (SNF) to jointly fund the endeavor, including a dedicated project office in Bern. Unfortunately, Jack Eddy had to step down for personal reasons soon after the inauguration of PAGES, but Herman Zimmerman, program manager at the NSF, was so convinced of the PAGES cause that he stepped in with great enthusiasm as PAGES Co-Director, together with Hans Oeschger, and also spent a significant amount of time in Bern to help run the office.

The first PAGES Science Plan (PAGES Scientific Steering Committee 1994) was structured both geographically and temporally along three pole-equator-pole (PEP) transects. It concentrated on the last 2000 years and multiannual to decadal variability, as well as the longer timescale of the last glacial/interglacial cycle. This was a structure that "still makes my head spin", said Herm Zimmerman recently. Despite, or likely also because of, this multidimensional structure, a large part of the paleoscience community immediately joined this endeavor, helping to make PAGES an IGBP showcase.

With a spirit of being open to all participants, PAGES soon provided unrivaled integrated datasets as well as new insights into the Earth system that could not have been achieved without paleoscience and the large-scale syntheses that PAGES facilitated; a modus operandi that continues today. It is fair to say that the long timescales of change that are central to the work of PAGES are

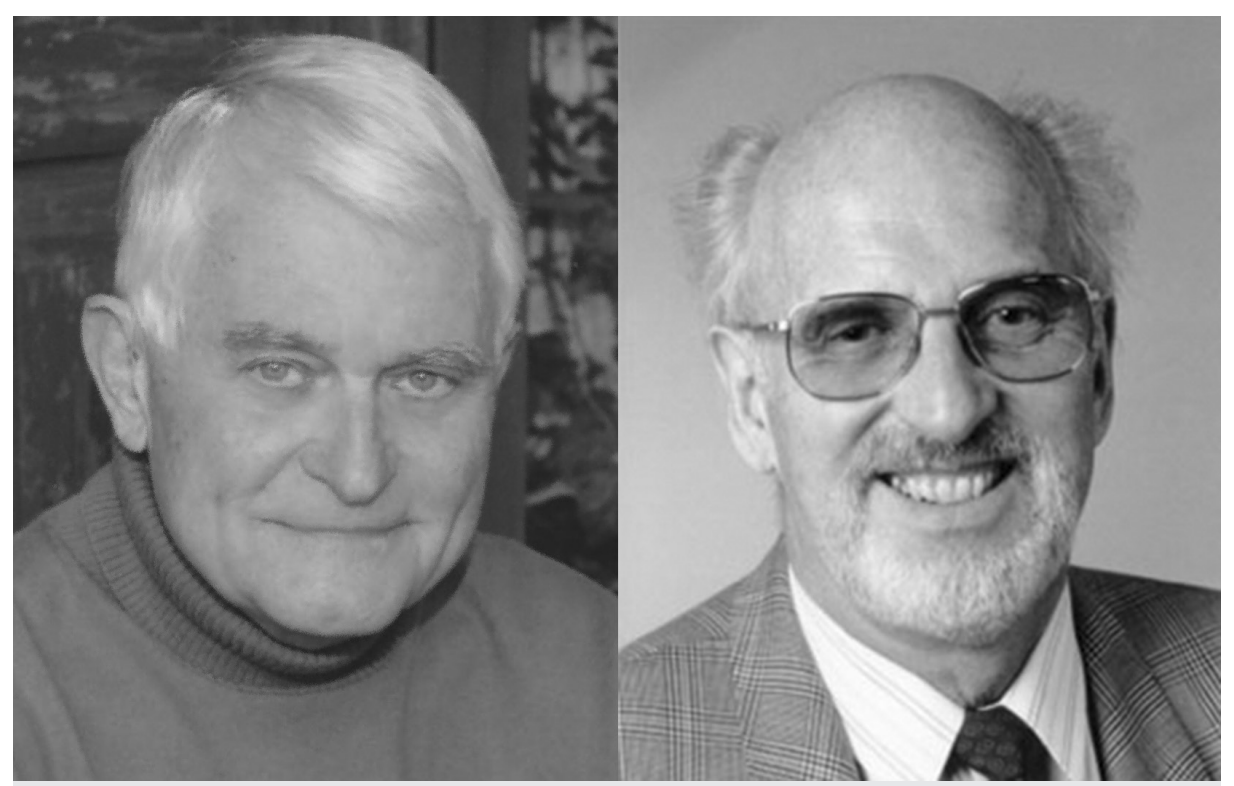

Figure 1: The two early PAGES visionaries Jack Eddy (left) and Hans Oeschger (right) 
also at the heart of the notion developed in IGBP that we live in the time of "The Great Acceleration" (Steffen et al. 2015), as many of the Earth system trends displayed in the IGBP Great Acceleration Plot (Fig. 2) could not have been quantified without paleoresearch. The long-term changes in the Earth system caused by humans in the course of the (late) Holocene are also the reason for the ongoing discussion to define this time as a new geological era, the so-called "Anthropocene", where geological evidence is overprinted by human actions.

The success of PAGES and especially of its innovative working groups clearly demonstrated that the whole is greater than the sum of its parts and that interdisciplinarity is key for producing the new knowledge required to assess global change from a paleo perspective. The roughly 1000 PAGES contributions that can be found today in the PAGES product database attest to the sustained timeliness and constant community-driven input that defines the success of PAGES. These products include a large number of contributions to Past Global Changes Magazine, reports, science plans, and information and outreach materials, but also about 400 peer-reviewed articles, of which more than $10 \%$ have been published in some of the highest-ranking journals in Earth and climate science.

The science objectives evolved over time, responding to new facets and dimensions of global change research, as reflected in the ternary diagram (Fig. 3) of the latest science plan (Kiefer et al. 2015). This plan focused the PAGES working groups within the three poles of "climate", "environment" and "humans", thus making PAGES more flexible, multi-dimensional, and responsive to the most pressing global change questions. Not only the science portfolio but also the services provided by PAGES have grown immensely over the years. This encompasses products both for the public and the paleoscience community (Past Global Changes Magazine articles, working group meetings, Open Science Meetings, etc.), and with the dedicated Young Scientists Meeting and the Early-Career Network, PAGES is now the home for early and senior paleoscientists alike (see Kiefer and Loutre, this issue, for more details).

\section{The Mid-PAGES Transition}

With climate-change science becoming increasingly mature and climate and environmental issues increasingly pressing, the call for more integrated and solutionoriented climate research became louder. In 2001, a first attempt was initiated to cross the borders between the four ICSU/ISSC programs (WCRP, IGBP, DIVERSITAS, and IHDP), through the so-called "Earth System Science Partnership". ESSP tried to provide an umbrella for cross-topical exchange and collaboration, but unfortunately never had the necessary traction to integrate these large, individually well-oiled science machines. In particular, the social science realm, which is a crucial element for transferring
Earth system science into policy-relevant and actionable science, did not receive the attention that was proportionate to the evergrowing global disaster humankind was and still is heading towards.

Accordingly, ICSU and ISSC (which in the meantime had joined to form the crossdisciplinary International Science Council) decided to redefine from scratch the way global change science was organized. The authors of this article participated in this painstaking process, spending many a day at transdisciplinary conferences, and workshops, in discussion groups, and writing a large number of reports, statements, and countless emails. The goal of all this activity was to design a programmatic structure of global change research that would encourage interdisciplinary collaboration and involve stakeholders outside of science in the research design, while at the same time enabling core projects, such as PAGES, to continue providing the crucial science basis without which educated political decisions cannot be made.

The result of this process was the global sustainability program Future Earth, which became the umbrella organization of PAGES after IGBP officially ended in 2015. The transition of PAGES to Future Earth was a learning process for all. For Future Earth, whose motivation was to support political action with scientific information, it was not immediately clear how a project like PAGES could become policy relevant, because

\section{THE GREAT ACCELERATION}

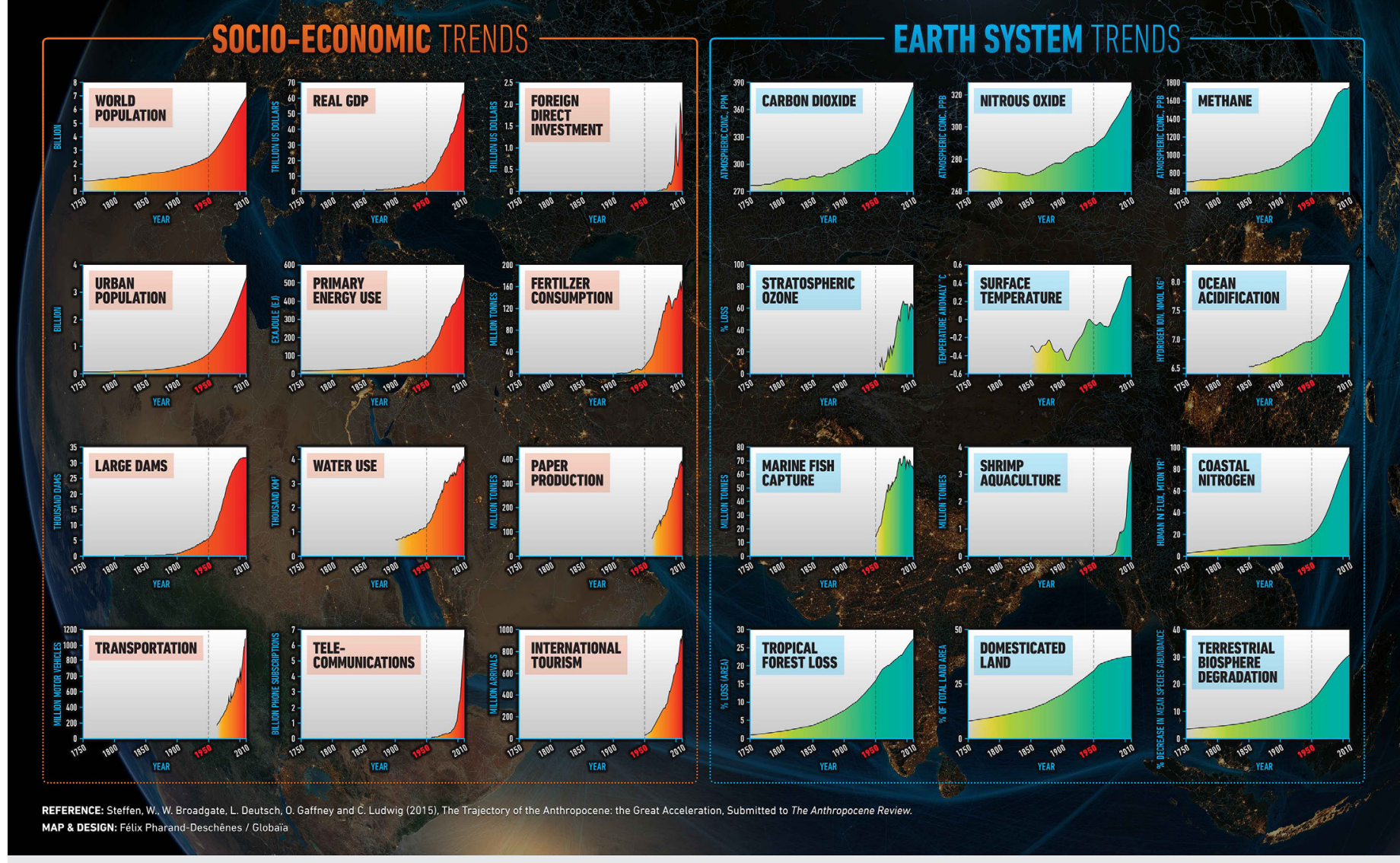

Figure 2: The great acceleration plot showing the rapid changes in socio-economic (left) and Earth system parameters (right) over the last 150 years (Steffen et al. 2015). 


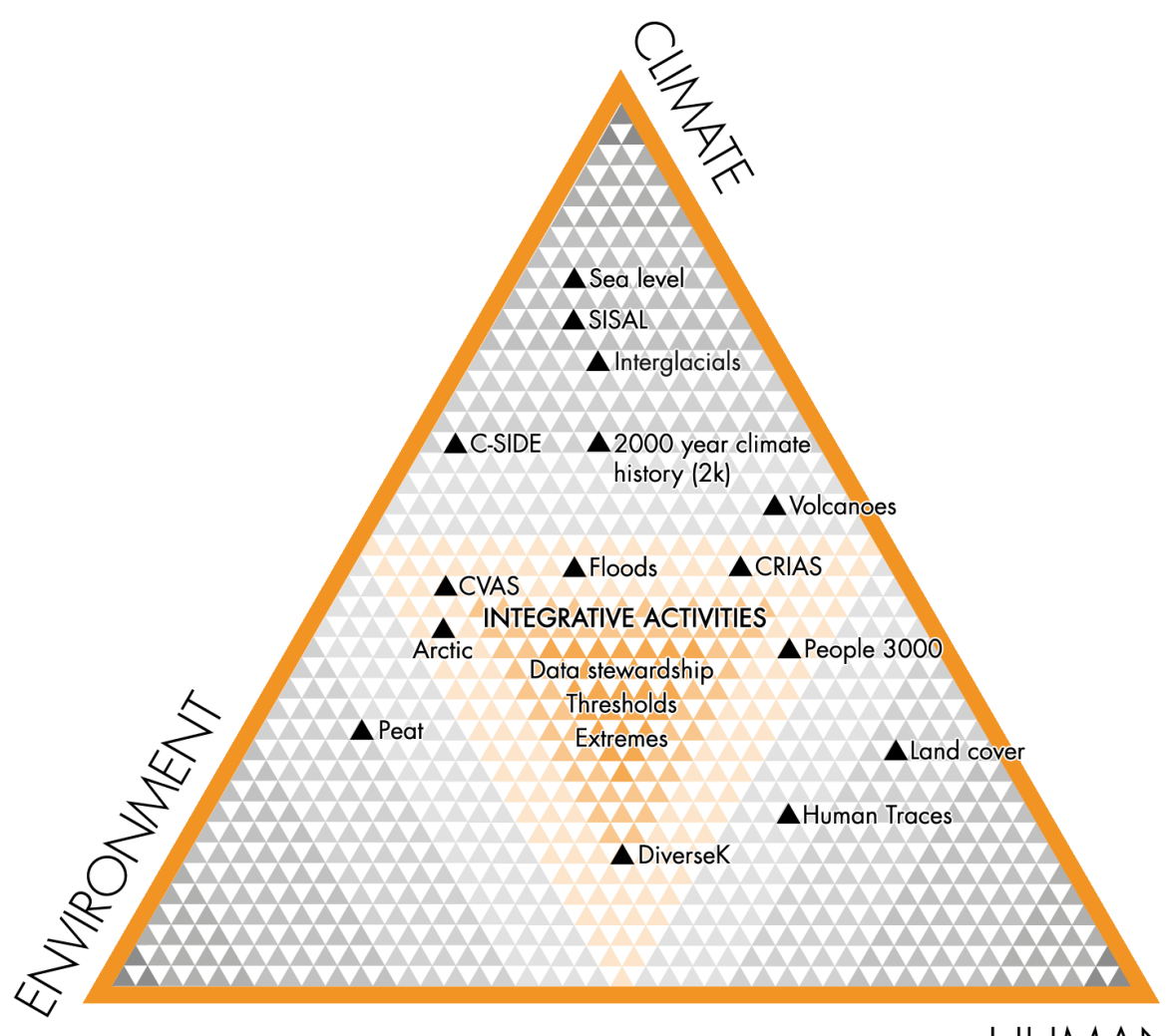

HUMANS

Figure 3: The PAGES ternary diagram showing the current PAGES working groups and their main focus in the three dimensional "phase space" of climate, humans, and the environment.

PAGES looks at time periods where humans were just one of many species on this planet and did not yet have comparable means to alter the entire Earth system. Eventually, understanding among the different fields and views assembled under Future Earth improved, helped along by PAGES' continuous delivery of first-class scientific products. For PAGES, the struggle at the beginning was with the concept of co-design, i.e. engaging the large range of stakeholders in PAGES' science. However, it is fair to say that by continuously scrutinizing its approach with respect to co-design and policy relevance, PAGES was able to focus even more attention on its initial goal of helping to solve global change issues.

\section{Financial glaciation/deglaciation}

PAGES had the privilege of being able to concentrate on scientific endeavors and breakthroughs, while the US and Swiss funders through their steady support provided the stability needed to initiate, establish, and nurture an international interdisciplinary network, including expansion of scientific connections and capacity in the developing world. Since the NSF and SNF only fund competitive grants, this naturally meant that PAGES had to earn its financial support by regularly submitting proposals that provided an account of previous achievements, explained the plans going forward, and justified the resources requested. While proposal writing increased the stress levels of the PAGES directors and co-chairs every four years, especially in the immediate presence of a deadline, this funding model and its inherent obligation to convince reviewers and funders clearly contributed to maintaining the excellence of PAGES over three decades.
The continuing success of these proposals in a highly competitive funding landscape attests to the quality of PAGES' work.

Another long-term supporter of PAGES was and is the University of Bern, which handles the accounting and human resources management of the PAGES International Project Office (IPO). In 2009, former PAGES co-chair Heinz Wanner also convinced the university to physically host the IPO. Sharing office space with the Technical Support Unit of IPCC Working Group I during its AR5 assessment cycle and, to this day, with the Oeschger Centre for Climate Change Research of the University of Bern, provides immeasurable opportunities for synergies and joint activities to promote (paleo) climate science.

Potentially related to the PAGES transition from IGBP to Future Earth, the last five years of PAGES' history were also a time of financial insecurity, and it was not clear if or how long PAGES would survive. After 25 years of US and Swiss funding, questions about the sustainability of this funding arrangement were raised by both the NSF and SNF. The issue on the Swiss side was not financial but only an organizational one, and since 2019 the Swiss funding has been provided by the Swiss Academy of Sciences. On the US side, NSF officials were afraid that the substantial PAGES funding would exacerbate increasing demand for their funds, with a view that PAGES' funding was in competition with individual investigator projects. Accordingly, NSF asked PAGES to secure funds from other programs and from other nations and organizations, to diversify the funding platform. While this request was justified, it was not easy to implement quickly, and this sadly led to the end of sustained US NSF funding in 2018.

But PAGES would not be PAGES if it were not able to mobilize its international science network and develop new funding channels. Convincing a national funder to support an organization such as PAGES is not as simple as we all wish it could be, because typical funding streams are usually not targeted at such a hybrid between a research project and an international science-facilitating organization such as PAGES. However, in 2019, the Chinese Academy of Sciences, which through a long line of PAGES Steering Committee members had always followed and supported the progress of PAGES, stepped in to provide a share of the funding. Thus, with joint funding from the Swiss Academy of Sciences and the Chinese Academy of Sciences for the next eight years, at levels similar to those in prior years, the PAGES story can continue.

Whether it continues to be a success story, however, is not so much a matter of the funding or its sources. More importantly, PAGES' success is crucially dependent on all of us who read this article: on the new generation of outstanding early-career scientists who bring novel ideas to PAGES and are highly motivated to do their own science but also be active in representing science in the public arena; on the senior scientists, to constantly realign and redefine PAGES to keep it at the forefront of global change research and to funnel paleoscience information into the highest policy levels; and, last but not least, on the dedicated team at the International Project Office in Bern, who commit their time and energy to providing paleoscientists with the best support possible to continue interdisciplinary paleoresearch to help save the planet.

\section{ACKNOWLEDGEMENTS}

We are immensely grateful to Herm Zimmerman, Ray Bradley, and Malcolm Hughes for their engaging stories and anecdotes about the early days of PAGES (which not all made their way into this article). Great thanks also to Heinz Wanner and Christian Pfister for some Swiss perspective of past PAGES changes.

\section{AFFILIATIONS}

${ }^{1}$ Climate and Environmental Physics, Physics Institute and Oeschger Centre for Climate Change Research, University of Bern, Switzerland

${ }^{2}$ Department of Earth and Atmospheric Sciences, School of Biological Sciences, University of Nebraska, Lincoln, USA

${ }^{3}$ College of Earth, Ocean, and Atmospheric Sciences, Oregon State University, Corvallis, USA

\section{CONTACT}

Hubertus Fischer: hubertus.fischer@climate.unibe.ch

\section{REFERENCES}

Bradley RS (Ed) (1989) Global Changes of the Past. University Corporation for Atmospheric Research, $514 \mathrm{pp}$

Kiefer T et al. (2015) PAGES Mag 23: 44-45

Meadows DH et al. (1972) The limits to growth. Universe Books, $205 \mathrm{pp}$

PAGES Scientific Steering Committee (1994) PAGES project status and work plan (1994-1998)

Steffen W et al. (2015) Anthropocene Rev 2: 81-98 